OPEN ACCESS

Edited by:

Anik Bhaduri,

Griffith University, Australia

Reviewed by:

Nidhi Nagabhatla,

United Nations University Institute for Water Environment and Health,

Canada

Daphne Gondhalekar Technische Universität München,

Germany

${ }^{*}$ Correspondence: Marianela Fader fader@bafg.de

Specialty section:

This article was submitted to

Freshwater Science,

a section of the journal

Frontiers in Environmental Science

Received: 26 June 2018 Accepted: 13 September 2018 Published: 12 November 2018

Citation:

Fader $M$, Cranmer $C$, Lawford $R$ and

Engel-Cox J (2018) Toward an

Understanding of Synergies and

Trade-Offs Between Water, Energy, and Food SDG Targets.

Front. Environ. Sci. 6:112

doi: 10.3389/fenvs.2018.00112

\section{Toward an Understanding of Synergies and Trade-Offs Between Water, Energy, and Food SDG Targets}

\author{
Marianela Fader ${ }^{1 *}$, Colleen Cranmer ${ }^{2}$, Richard Lawford ${ }^{3}$ and Jill Engel-Cox ${ }^{4}$ \\ ${ }^{1}$ International Centre for Water Resources and Global Change (UNESCO), Federal Institute of Hydrology, Koblenz, Germany, \\ ${ }^{2}$ International Union for Conservation of Nature (Laos), Savannakhet, Laos, ${ }^{3}$ Morgan State University, Baltimore, MD, \\ United States, ${ }^{4}$ National Renewable Energy Laboratory, Golden, CO, United States
}

Achieving the targets set out in the UN Sustainable Development Goals (SDG) will require committed efforts by nations and organizations over the coming decade. To determine which actions work most harmoniously within funding, infrastructure development, and implementation of three closely aligned goals, we conducted an assessment to identify where the greatest synergies may occur and where conflicting resource needs create trade-offs that may threaten SDG success. The SDGs each have several targets that need to be realized for the goal to be reached. In the present study, we developed a methodology where each target of the SDG 2 (food), 6 (water), and 7 (energy) was analyzed for its input requirements, infrastructure needs, and the risks and benefits for the provision of ecosystem services. Then the targets were compared pairwise and a total score of interaction was calculated to determine different levels of synergies and trade-offs for every pair. In some cases targets were mutually supportive, in other cases there were no interactions among the targets, and for some areas the targets were in conflict with each other. For example, targets 2.5 (maintain genetic diversity), 6.5 (implement integrated water resources management) and 7.a (enhance international cooperation to facilitate access to clean energy) have no conflicts with other targets and have different levels of synergies with most of the other targets. On the contrary, various targets of SDG 2, and especially the target 2.b (correct and prevent trade restrictions), are in slight conflict with other targets by potentially overusing resources needed by other targets or threatening ecosystem services. Our approach confirms the general belief that SDG 6 (water) has the highest number of potential synergies (a total of 124). Thus, achieving the water targets will make it continuously easier to achieve other targets. While the results may need to be adapted for a specific locality or country, overall they provide an improved understanding of the interactions between the targets. The value of the study lies in the quantitative methodology as it can be used as a replicable analysis for any level of work on SDG implementation.

Keywords: water-food-energy nexus, SDGs 2, 6, 7, trade-offs among SDG targets, synergies between SDG tagets, sustainable development goals - SDGs 


\section{INTRODUCTION}

With the aim of reaching economic, social and environmental sustainability, improving life quality for all and unfolding human potentials, countries of the world agreed in September 2015 to 17 Sustainable Development Goals (SDGs) to be achieved by 2030. A total of 169 targets have been established to provide a basis for major advances toward achieving the overall goals through concrete objectives, such as increasing renewable energy, doubling agricultural productivity, or improving water quality. Indicators have been defined for each target to provide a measure of the progress that is being made toward them; some of those indicators continue to be developed and approved. Three of the SDGs refer specifically to food (SDG 2), water (SDG 6) and energy (SDG 7). These three goals are intrinsically linked, as are the resource management, infrastructure development and political measures needed to reach them. The interconnectedness between these sectors implies the potential for synergies but also the risk of trade-offs. Synergies are understood in this study as positive effects of a target achievement on ecosystem services that would, in turn, allow reaching other targets, or mutually beneficial development of infrastructure and policies, which can facilitate SDG implementation. Trade-offs are created where one target intensively uses resources necessary for the achievement of another target, or when environmental degradation caused by the achievement of one target limits the chances to achievement of another target. For example, the path(s) taken by individual nations to achieve the targets for energy could affect their ability to achieve the water and food targets in either a positive or negative way. To achieve the goals while minimalizing tradeoffs, there will need to be a reliance on policies that take into consideration the interdependence between water, energy and food.

Fortunately these developments have come at a time when policy makers (Pardoe et al., 2017; Scott, 2017), as well as the science community (Pittock et al., 2015; Endo et al., 2017) are becoming increasingly aware of the interlinkages between water, energy, and food through Water-Energy-Food (WEF) Nexus studies. However, while WEF Nexus studies have become common, there are very few assessments analyzing synergies and risks between SDG targets. A report prepared in 2016 by the UNWater Task Force provides a first evaluation of the interlinkages of SDG 6 (focused on water) with the other SDGs. Focusing on the three dimensions of sustainable development, namely social, economic and environmental, the brief captures the complex nature of the SDGs, giving a qualitative snapshot of the many considerations that go into the success of a single SDG (6); an inclusive assessment across all SDGs will help governments establish the mechanisms and procedures needed to address trade-offs (UN-Water, 2016). A 2017 study on wastewater highlights that target 6.3 , improve water quality by reducing pollution and eliminating dumping and minimizing the release of hazardous chemicals and materials, will challenge SDG 7 targets as collection and treatment of wastewater requires a significant amount of energy; achieving this target, while acknowledging SDG 7, will be financially burdensome on low-income countries that may not have access to the technological upgrades needed
(Connor et al., 2017). Nilsson et al. (2016) developed a systematic way for policy makers to map out target interactions so that they can identify which stakeholders will need to be involved to create synergies amongst the SDGs. They designed a seven-point scale that indicates if a target is inextricably linked to the achievement of another goal (indivisible) or if the target clashes with another goal (counteracting). Coopman et al. (2016) use a similar methodology to assess SDG 12 ("Sustainable consumption and production") against the other 16 SDGs. They developed a methodology to analyse the implications of the policy measures needed for achieving the SDGs by focusing on the linkages between the targets in SDG 12 and the other SDG targets relevant to it. Four analysts evaluated and assigned a rating to the linkages separately and categorized target interactions into three categories, supporting, enabling/disenabling, and relying. Pradhan et al. (2017) quantified SDG target synergies and trade-offs by applying a statistical correlation analysis to the country and country-disaggregated data from the United Nations Statistics Division. The interactions for each SDG pair are analyzed and ranked at country and global scales, so it provides a broad analysis of SDG interactions, showing the varied compatibilities between all 17 SDGs. The approach used in this paper is more focused, analyzing interactions of the three SDGs that typically have the strongest nexus (Bhaduri et al., 2015; Biggs et al., 2015).

Our analysis works to build on Nilsson et al. (2016) by expanding their scale and establishing a systematic approach to define where each pair of WEF targets are on that scale. Similar to Pradhan et al. (2017), we aim to quantify synergies and tradeoffs but our assessment focuses on target interactions and does not use indicator data. The aim here is to be able to improve society's understanding of how actions can be taken in one sector to benefit that sector and one or both of the other sectors. At the same time, we aim to warn nations about the risks and lost benefits from a lack of communication and coordination between sectoral strategies. This approach is based on resources and infrastructure needs to reach every WEF target, as well as potential benefits and risks for ecosystem services arising from measures taken to reach such targets. The nature of our methodology allows for replication across varying temporal and spatial scales within the WEF Nexus.

\section{METHODS}

This section summarizes the methodology; full details and explanations can be found in the Supplementary Material. Figure 1 shows the steps developed in this study to quantify synergies and trade-offs between two SDG targets.

\section{Evaluation of Target Needs and Impacts}

Based on the expert knowledge of the authors, every target is first evaluated regarding inputs needs in three domains (1) water, (2) land and soil, and (3) electricity and fuel. If any component of that resource group is needed to reach the target $\mathrm{a}-1$ is assigned, otherwise, a zero is assigned.

After that the infrastructure requirements are assessed in three domains (1) health care and hospitals, (2) education, technology, 


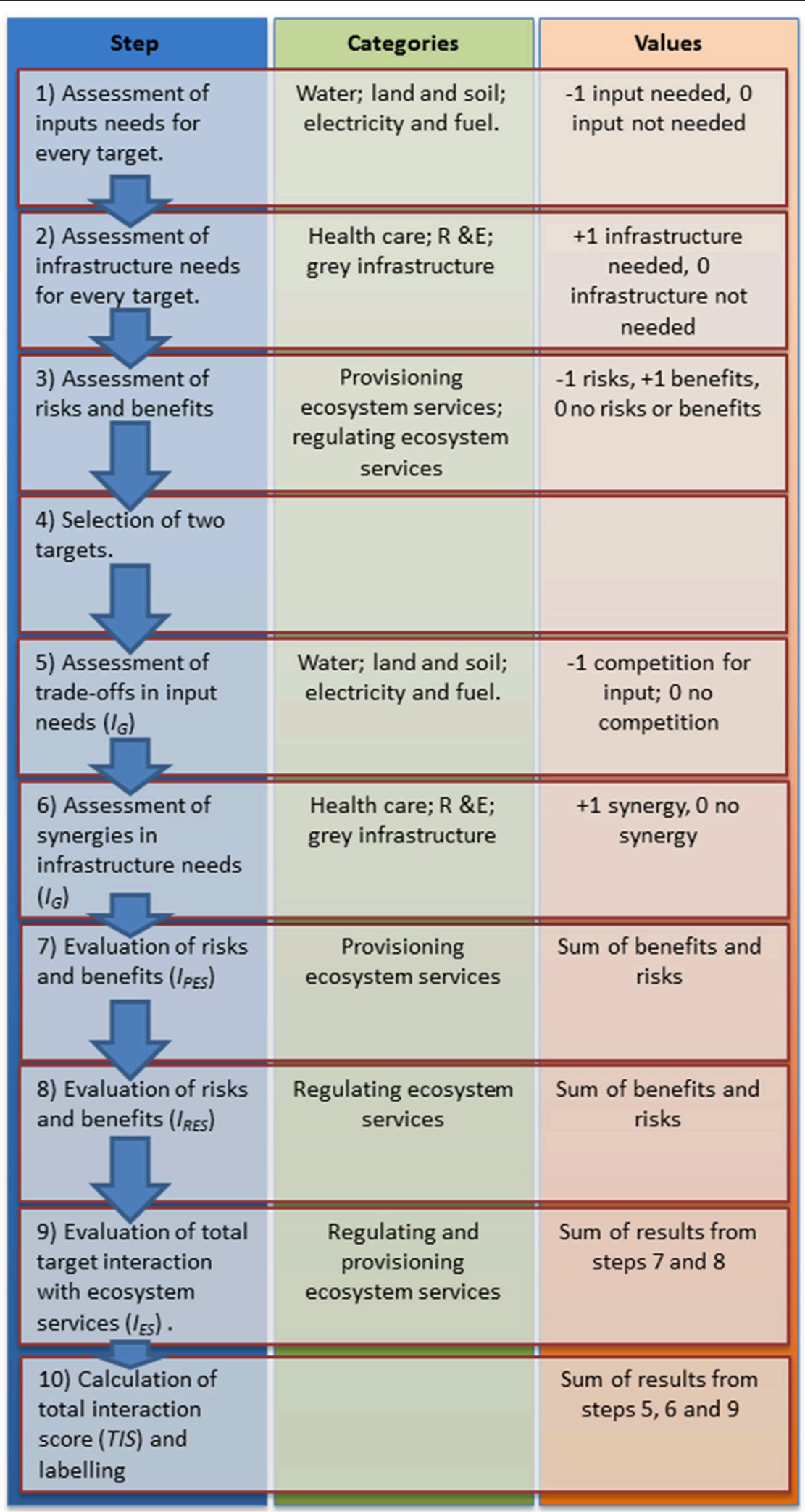

FIGURE 1 | Steps for assessment of synergies and trade-offs between two SDG targets. 
and research ("R\&E"), (3) streets, pipes, rails, airports, seaports, channels, dams, energy production, sewage, and water treatment ("gray infrastructure" for simplification). If any component of that infrastructure group is required a +1 is assigned, otherwise, a zero is assigned.

Following, for every SDG target it was investigated if its achievement would imply a risk or produce benefits for provisioning and regulating ecosystem services. Supporting ecosystem services were included in the evaluation of regulating services. While it is recognized that cultural ecosystem services are an important consideration, it was not possible to include them in this study due to the multicultural diversity of nearly all nations and the complexity of their evaluation. If there are risks for regulating or provisioning ecosystem services, the value -1 is assigned, if there are benefits, the value +1 is assigned. Otherwise zero is assigned.

\section{Assessing Trade-Offs and Benefits Between Two Targets}

First, an arbitrary pair of SDG targets is selected. If the achievement of both targets requires the same group of inputs (e.g., water), it is considered that a competition for this resource will occur and the value -1 will be assigned for the interaction, otherwise it will be zero. The process is repeated for the three resource domains (water; land, and soil; electricity and fuel).

Second, if both targets require the presence or the development of the same group of infrastructure in order to be achieved, it is considered that the infrastructure developed for the achievement of one of the targets can be also used to achieve the second target. In that case it is considered that there would be infrastructural synergies when intending to achieve both targets and the value 1 will be assigned for the interaction; otherwise it will be assigned a zero. The process is repeated for the three infrastructure domains (health care and hospitals; R \& E; gray infrastructure).

Third, risks and benefits are evaluated against each other, respectively for provisioning and regulating ecosystem services as well as for the total interaction of the targets with ecosystem services.

Finally, the total interaction score (TIS) between two targets was calculated as the sum of competition for input requirements, synergies in infrastructure development and the total effects (risks and benefits) on ecosystem services. The labeling of the results for TIS is based on an extension of the categories presented in Nilsson et al. (2016) to allow a more detailed description fitting the theoretical rage of results. These categories are defined in Table 1, showing that positive TIS represent different levels of synergies between the targets. The same way, negative TIS represent trade-offs between the targets. Table 2 shows an example of the calculation of a two target interactions and total interaction score TIS.

\section{RESULTS}

The results of this study include three aspects: the interactions between every pair of targets, the number of positive, neutral, and
TABLE 1 | Categories for defining interaction values between targets.

\begin{tabular}{lll}
\hline Interaction & Name & Explanation \\
\hline-4 & Canceling & Makes it impossible to reach another goal \\
-3 & Restricting & Obstructs the achievement of another goal \\
-2 & Counteracting & Clashes with another goal \\
-1 & Constraining & Limits options on another goal \\
0 & Consistent & No net significant positive or negative interactions \\
1 & Enabling & Creates conditions that further another goal \\
2 & Reinforcing & Aids the achievement of another goal \\
3 & Supporting & Strongly facilitates the achievement of another goal \\
4 & Indivisible & Inextricably linked to the achievement of another goal
\end{tabular}

negative interactions as well as the average of interaction for every SDG target, and the same parameters aggregated by SDG.

Table 3 shows the TIS for all targets of SDG 2, 6 and 7. The matrix is color-coded to match the values given to each interaction. Each target interaction is mirrored in the matrix, a pair of targets whether leading from the $\mathrm{x}$ axis or $\mathrm{y}$-axis will give the same result. The most noticeable result is that there are no restricting, counteracting and canceling interactions. This could mean that the SDGs are well-designed or that the analysis was too lenient on the implications associated with ecosystem services. Another reason for the lack of very strong negative interactions is that the risk and benefits, and the input competition and infrastructure synergies compensate each other.

Figure 2 shows statistics for every target of the three SDG separately and aggregated for the three SDG. There are a total of 166 positive interactions vs. a total of 26 negative interactions. The positive interactions (synergies) have higher values than the negative ones, with 59 positive interactions labeled as "supporting" $(+3)$, and all negative interactions are in the level of "constraining" $(-1)$. The average of total interactions is 1.5 and the median is 2.0 , establishing the overall interactions between these three SDGs between enabling and reinforcing. Considering every SDG separately, the average of the interactions for every SDG has values of $>1$ (1.8 for SDG 7, 1.1 for SDG 2, 1.8 for SDG 6) (Figure 2). Our approach confirms the general belief that SDG 6 (water) has the highest number of potential synergies; this goal has a total of 124 positive interactions with an average of positive interactions of +2.1 ("reinforcing"). Thus, achieving the water goals will make it continuously easier to achieve more goals and targets, including those outside of the WEF nexus.

\section{Negative Interactions}

The SDG with the highest negative interaction count is SDG 2 (End hunger, achieve food security, and improved nutrition and promote sustainable agriculture) with 26 negative interactions (Figure 2). All negative interactions in the matrix are connected to a target of SDG 2. Food related targets are highly dependent on the use of other resources and reaching them with unsustainable techniques (as it has been done in conventional agriculture) has the potential of damaging ecosystems. Therefore, these results indicate that the implementation of SDG 2, while fundamental for food security, must be done with care. Despite this, SDG 2 
TABLE 2 | Example of two targets interaction assessment.

\begin{tabular}{|c|c|c|c|c|c|c|c|c|c|c|c|}
\hline \multirow[t]{2}{*}{ Targets } & \multicolumn{3}{|c|}{$\begin{array}{l}\text { Inputs needs } \\
-1 \text { means input needed, } 0 \\
\text { input not needed }\end{array}$} & \multicolumn{3}{|c|}{$\begin{array}{c}\text { Infrastructure needs } \\
1 \text { means infrastructure needed, } 0 \text { means not } \\
\text { needed }\end{array}$} & \multicolumn{2}{|c|}{$\begin{array}{c}\text { Provisioning } \\
\text { ecosystem services }\end{array}$} & \multicolumn{2}{|c|}{$\begin{array}{c}\text { Regulating } \\
\text { ecosystem services }\end{array}$} & \\
\hline & water & $\begin{array}{l}\text { Land and } \\
\text { Soil }\end{array}$ & $\begin{array}{l}\text { Electricity } \\
\text { and fuel }\end{array}$ & $\begin{array}{l}\text { Health Care } \\
\text { and hospitals }\end{array}$ & $\begin{array}{c}\text { Education, technology } \\
\text { and research }\end{array}$ & $\begin{array}{l}\text { Streets, pipes, rails, } \\
\text { airports, channels, } \\
\text { dams, sewage, ports, } \\
\text { water treatment }\end{array}$ & Risks & Benefits & Risks & Benefits & \\
\hline 6.3 & 0 & 0 & -1 & 0 & 1 & 1 & 0 & 1 & 0 & 1 & \\
\hline 2.1 & -1 & -1 & -1 & 1 & 1 & 1 & -1 & 1 & -1 & 0 & \\
\hline \multirow[t]{2}{*}{$\begin{array}{l}\text { Trade- } \\
\text { off/synergy }\end{array}$} & 0 & 0 & -1 & 0 & 1 & 1 & & 1 & & 0 & $T / S=+2$ \\
\hline & & & & & & & \multicolumn{4}{|c|}{+1} & \\
\hline
\end{tabular}

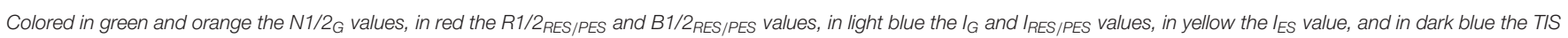
value. See equations 1 to 4 in the Suplementary Material.

TABLE 3 | Total interaction score (TIS) between targets of SDG 2, 6 and 7.

\begin{tabular}{|c|c|c|c|c|c|c|c|c|c|c|c|c|c|c|c|c|c|c|c|c|c|}
\hline & 6.1 & 6.2 & 6.3 & 6.4 & 6.5 & 6.6 & 6.a & 6.b & 2.1 & 2.2 & 2.3 & 2.4 & 2.5 & 2.a & 2.b & 2.c & 7.1 & 7.2 & 7.3 & 7.a & 7.b \\
\hline 6.1 & & 1 & 2 & 2 & 3 & 1 & 1 & 2 & 0 & 0 & 0 & 1 & 3 & 3 & -1 & 1 & 2 & 2 & 2 & 3 & 2 \\
\hline 6.2 & 1 & & 2 & 2 & 3 & 1 & 1 & 3 & 1 & 1 & 1 & 1 & 3 & 3 & -1 & 1 & 2 & 2 & 2 & 3 & 2 \\
\hline 6.3 & 2 & 2 & & 2 & 3 & 2 & 1 & 3 & 2 & 2 & 2 & 2 & 3 & 3 & 0 & 1 & 2 & 3 & 2 & 3 & 2 \\
\hline 6.4 & 2 & 2 & 2 & & 3 & 2 & 1 & 3 & 2 & 2 & 2 & 2 & 3 & 3 & 0 & 1 & 2 & 3 & 2 & 3 & 2 \\
\hline 6.5 & 3 & 3 & 3 & 3 & & 2 & 2 & 3 & 3 & 3 & 3 & 3 & 3 & 3 & 0 & 1 & 3 & 3 & 2 & 3 & 3 \\
\hline 6.6 & 1 & 1 & 2 & 2 & 2 & & 2 & 1 & -1 & -1 & -1 & 0 & 2 & 2 & -1 & 1 & 2 & 1 & 2 & 2 & 1 \\
\hline $6 . a$ & 1 & 1 & 1 & 1 & 2 & 2 & & 2 & 0 & 0 & 0 & 1 & 2 & 2 & -1 & 1 & 1 & 2 & 2 & 2 & 1 \\
\hline 6.b & 2 & 3 & 3 & 3 & 3 & 1 & 2 & & 2 & 2 & 2 & 2 & 3 & -1 & 3 & 1 & 3 & 2 & 2 & 3 & 3 \\
\hline 2.1 & 0 & 1 & 2 & 2 & 3 & -1 & 0 & 2 & & -1 & -1 & 0 & 3 & 1 & -1 & -1 & 1 & 1 & 1 & 3 & -1 \\
\hline 2.2 & 0 & 1 & 2 & 2 & 3 & -1 & 0 & 2 & -1 & & -1 & 0 & 3 & 1 & -1 & -1 & 1 & 1 & 1 & 3 & -1 \\
\hline 2.3 & 0 & 1 & 2 & 2 & 3 & -1 & 0 & 2 & -1 & -1 & & 0 & 3 & 1 & -1 & -1 & 1 & 1 & 1 & 3 & -1 \\
\hline 2.4 & 1 & 1 & 2 & 2 & 3 & 0 & 1 & 2 & 0 & 0 & 0 & & 3 & 3 & 0 & 1 & 2 & 2 & 2 & 3 & 1 \\
\hline 2.5 & 3 & 3 & 3 & 3 & 3 & 2 & 2 & 3 & 3 & 3 & 3 & 3 & & 3 & 0 & 1 & 3 & 3 & 2 & 3 & 3 \\
\hline 2.a & 3 & 3 & 3 & 3 & 3 & 2 & 2 & -1 & 1 & 1 & 1 & 3 & 3 & & -1 & 0 & 3 & 3 & 2 & 3 & 2 \\
\hline $2 . b$ & -1 & -1 & 0 & 0 & 0 & -1 & -1 & 3 & -1 & -1 & -1 & 0 & 0 & -1 & & -1 & -1 & -1 & -1 & 0 & -1 \\
\hline 2.c & 1 & 1 & 1 & 1 & 1 & 1 & 1 & 1 & -1 & -1 & -1 & 1 & 1 & 0 & -1 & & 1 & 1 & 1 & 1 & 0 \\
\hline 7.1 & 2 & 2 & 2 & 2 & 3 & 2 & 1 & 3 & 1 & 1 & 1 & 2 & 3 & 3 & -1 & 1 & & 3 & 2 & 3 & 2 \\
\hline 7.2 & 2 & 2 & 3 & 3 & 3 & 1 & 2 & 2 & 1 & 1 & 1 & 2 & 3 & 3 & -1 & 1 & 3 & & 2 & 3 & 3 \\
\hline 7.3 & 2 & 2 & 2 & 2 & 2 & 2 & 2 & 2 & 1 & 1 & 1 & 2 & 2 & 2 & -1 & 1 & 2 & 2 & & 2 & 2 \\
\hline 7.a & 3 & 3 & 3 & 3 & 3 & 2 & 2 & 3 & 3 & 3 & 3 & 3 & 3 & 3 & 0 & 1 & 3 & 3 & 2 & & 3 \\
\hline 7.b & 2 & 2 & 2 & 2 & 3 & 1 & 1 & 3 & -1 & -1 & -1 & 1 & 3 & 2 & -1 & 0 & 2 & 3 & 2 & 3 & \\
\hline
\end{tabular}

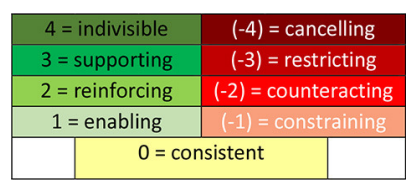

has a total of 106 positive interactions, reaching those targets will generally help in reaching the water and energy targets.

The target with the most negative interactions (13 in total) is 2.b (Correct and prevent trade restrictions and distortions in world agricultural markets), all of them are labeled as "constraining" (Figure 2 and Table 3 ). This target is also the only one with a negative average of interactions $(-0.4)$. This reflects mainly the potential risks for ecosystem services arising from a likely reorganization of food production patterns following market liberalization. For example, if the European Union would stop subsidizing their agricultural sector, production in other regions (e.g., South America) would become more profitable for exports and the consequent expansion and intensification of agriculture could lead to soil degradation, deforestation, and other environmental problems, if the change is not combined with strong environmental protection laws. It is worthwhile noticing that in this hypothetical case, agriculture in Europe may become less profitable, leading to abandonment of agricultural 


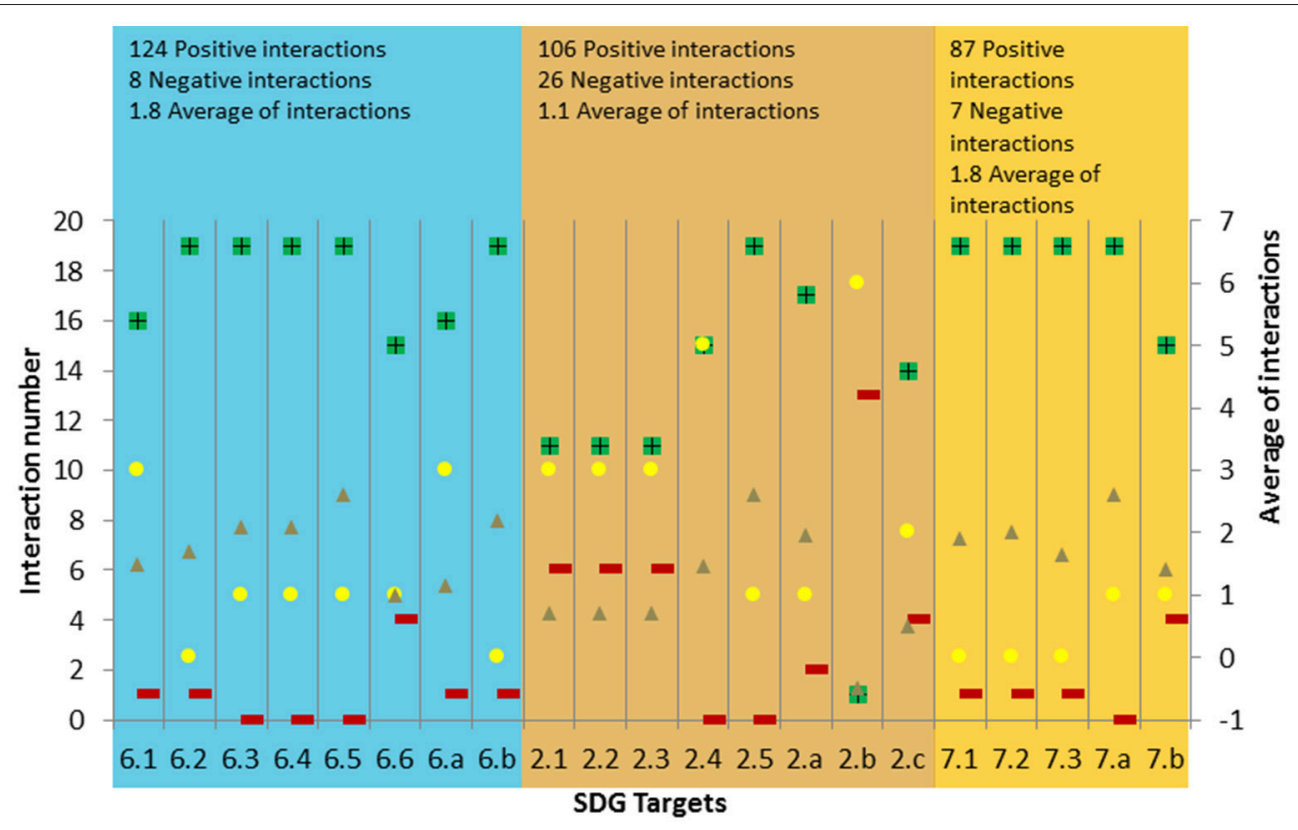

$\begin{array}{cccc}\text { \# Positive interactions } & \text { - Negative interactions } & \text { Neutral interactions } & \Delta \text { Average of interactions } \\ \text { Total }=166 & \text { Total }=26 & \text { Total }=62 & \text { Total average }=1.5\end{array}$

FIGURE 2 | Interaction number (positive, neutral and negative) (left y-axis) and average of total interaction value (TIS) (right X-axis) for SDG targets of the water (blue), food (orange) and energy (yellow) goals (x-axis). The values written on the upper part of the graph correspond to total positive, negative and average of interactions per SDG. The values below the legend represent the total number of positive, negative, neutral interactions, and average of interactions, for all SDG targets taken together.

land, possible succession of natural ecosystems and reduction of provisioning ecosystem services. Potential socio-economic changes in both regions would also be very likely.

Table 3 shows that target 2.1 (End hunger) in particular may have a constraining effect on targets 2.2 (end malnutrition) and 2.3 (double the agricultural productivity in terms of income and labor) because of the potential negative consequences for regulating ecosystem services if food security would be achieved by intensification or deforestation. While there is clear potential for synergies in terms of infrastructure use and development that are captured in our estimation, there are also similar input needs that can cause competition for resources. This is the case since water, land and soil, and electricity and fuel are all needed in mass amounts to produce the food necessary to address hunger, malnutrition and to double agricultural productivity. This result is based on the assumption that the fight against rural poverty, malnutrition, and hunger in the framework of the current economic system is likely to be addressed by increases in cheap food production and not by redistribution of resources, means, or food. Achievement of these targets produces benefits for provisioning ecosystem services in the form of food production while at the same time has a negative, draining effect on resources and implies a risk to regulating ecosystem services such as issues of water quality and over-extraction. The water and land needs required from targets $2.1,2.2$, and 2.3 have a constraining $(-1)$ effect on target 6.6, protect and restore water-related ecosystems, including mountains, forests, wetlands, rivers, aquifers, and lakes. The goal to protect ecosystems yet establish high yield agriculture that satisfies global hunger issues is challenging, especially if high yields are achieved by conventional (agrochemical intensive) agriculture. However, extensive technology advancements and policy implementation can help to achieve all these targets in a sustainable manner (Gupta et al., 2014). The above findings have implications for the WEF Nexus because it emphasizes the critical role economics and trade policies play in production of food. If the demands for food diminish in any one country the demands for water and energy resources will also decrease. Both the WEF Nexus and the SDGs would benefit from a better understanding of the interactions of economic policy with the biophysical aspects of the WEF Nexus.

\section{Positive Interactions}

There is no indivisible interaction ( +4 value) in the matrix, indicating that in every target pair there is at least one area with possible risks for ecosystem services or competition for resources (Table 3). However, many targets have numerous positive interactions and all targets except 2.b have averages of interactions $>0$ (Figure 2).

Certain targets are notably positive across all their target interactions; what the target is looking to achieve will ultimately aid the other targets in their success. The targets with the highest averages of interactions are 7.a (enhance international cooperation for clean energy), 2.5 (maintain genetic diversity) and 6.5 (implement integrated water resource management) (Figure 2). An additional pattern emerges amongst the highly 
positive targets: they are mostly advocating cooperation and are policy focused. For example 7.a, is assessed as having only positive interactions, with the exception of one consistent (0) interaction with $2 . \mathrm{b}$ (correct and prevent trade restrictions and distortions in world agricultural markets). Targets 7.a, 6.5 and 2.5 have also the highest average of interactions (2.6).

Target 7.a. takes a cooperative approach; achieving international cooperation in energy technology will increase knowledge transfer and quicken the pace at which these technologies are created, shared, and implemented. Shared infrastructure needs additionally create a positive value between targets due to cost sharing opportunities. Thus, achieving 7.a will be beneficial for all energy, water and food targets, with the exception of 2.b (which has a consistent interaction equal to 0 ). Achieving 7.a will also produce benefits for both provisioning and regulating ecosystem services; energy infrastructure aids in the provisioning of food and water resources, and advances in energy efficient buildings such as green roofs will help to regulate climate extremes. The success of 7. a will have a cascading influence on other targets. The use of fresh water within the energy industry impacts water quality and quantity, such as the large amounts of water used in the process of converting coal or uranium into electricity (Yillia, 2016). Efficient and clean energy use technologies will typically result in a lower burden on water input needs (Cooley and Donnelly, 2013). The water-efficiency established from these practices can lend themselves to agricultural needs, furthering SDG 2 targets.

Target 6.5, the implementation of integrated water resource management, is supportive amongst most interactions. It is another example of a cooperative, policy-focused target that does not require significant input needs, and creates benefits for provisioning and regulating ecosystems. The overall supporting effect it has on the WEF targets could be attributed to the similarities between nexus thinking and an integrated water resources management approach. Both champion sustainable resource development within society by taking on a holistic environmental, economic and social view (Benson et al., 2015).

While it is gratifying to see these synergies among the SDGs, the possibilities would be much easier to realize at the national level if each country had a strong WEF Nexus implementation framework in place to ensure all three sectors and SDGs were supported by a coherent policy that was based on a broad understanding of all the factors that could affect each sector.

\section{DISCUSSION}

This study presents a quantitative approach to estimate the strength of potential trade-offs and synergies between the water, food and energy SDG targets. In addition to elucidating the relationships between the targets at the macroscale, the methodology can be adapted to a particular region where it could provide useful insights for decision makers and local implementation plans. Some interactions among targets are discussed in the following paragraphs to show the complexity and nesting of relationships between SDGs in the WEF Nexus framework.
The links between food targets are complex. Target 2.3 (double the agricultural productivity and incomes of small-scale food producers) must be achieved at the same time as Target 2.1 (end hunger) and Target 2.2 (end malnutrition). Higher food production (at least in the short term) may be achieved by expanding the use of agro-chemical and increasing agricultural outputs through larger farms with more mechanization, and the wider use of Genetically Modified Organisms (GMO) (Adenle and Ammann, 2015). However, Target 2.3 constrains this approach by requiring more small-scale producer development which may also reduce environmental degradation and health risks (e.g., Sheahan et al., 2016). This insight derived from the results of this analysis, would favor satisfying the requirements of all three targets by promoting sustainable (organic), smallscale agriculture which can enhance agricultural productivity while reducing environmental impacts and protecting smallscale food producers (Rockström et al., 2017). GMOs carry the added risk that they could threaten the long-term sustainability of plant and animal biodiversity (Azadi et al., 2015), affecting the achievement of target 2.5. The approach outlined here provides a quantitative basis for initiating discussions about different pathways for reaching targets while minimizing tradeoffs, especially needed in developing countries with food insecure situations.

Target $2 \mathrm{~b}$ which is neutral or in some conflict with most of the other targets seeks to minimize trade restrictions. However, some of the food targets as well as the energy and water targets may require protection from uncontrolled globalization to be achieved. Interactions with target $2 . b$ are especially difficult to analyse since a reorganization of trade patterns would most likely lead to changes in land use and income, and to diverse, spatially heterogeneous consequences for ecosystem services and food production (e.g., Dean, 2002; Fader et al., 2011). The famous debate on "land sparing" vs. "land sharing" reflects also the complexity of this issue (e.g., Tscharntke et al., 2012). Here again, a detailed application of our approach needs to be undertaken in future studies, accounting for scenarios on which countries would minimize trade restrictions (and how), and what that would mean for the analyzed country and its trade partners in terms of land use, water, energy, and food security.

Target 6.3 deals with water quality which is affected by the by-products of many energy and agricultural activities. This target is shown to have synergies with almost all other targets, due to low competition for water, land and energy, and benefits for ecosystem services. Water quality is often diminished by using water to dilute and dispose thermal and chemical by-products from thermal power plants. As a result, water treatment is needed to bring water back to a safe and usable state. This requires substantial capital investments and continuous energy inputs. In farming, fertilizers, and pesticides from farm operations find their way into water courses and eventually to lakes or coastal areas where their accumulated effects result in phytoplankton blooms and even eutrophication. Overall, reduced use of thermal power stations to produce electrical energy as a result of increasing share of non-thermal renewables as well as the growth of organic 
agriculture and the development of environmental laws should improve the general trend in water quality. However, as noted in ICSU/ISSC, 2015, both emerging and developed countries will likely have to use different approaches to achieve target 6.3. Thus, testing our approach in future studies by contrasting different implementation pathways with stakeholder participation would be desirable and useful.

Water quantity and accessibility are as important as the water quality issues. Agricultural needs plus an easily accessible supply of energy may create a situation where water resources are overused. Areas with food insecurity are often those with the greatest water loss and therefore smart approaches to water use in agriculture are needed (Ringler et al., 2013). Providing lowcost energy for irrigation is a case where a silo approach is used. In particular, there has been a large growth in groundwater extraction in India and South Asia due to irrigation strategies built from flat rate tariffs and subsidies on power to boost the agricultural sector (Lele, 2013). If similar approaches are taken when attempting to achieve SDG 2, many of SDG 6's targets will not be met. Coherent water-energy policies are essential (Yillia, 2016) if food production is going to increase in a sustainable manner. The WEF Nexus approach is intended to address this problem specifically by encouraging more communication and joint planning between the three sectors to avoid these resource use conflicts.

When considering clean energy (SDG 7) in the context of water and food, attention must be given to the method of production of the clean energy. Target 7.a defines clean energy as "renewable energy, energy efficiency and advanced, and cleaner fossil-fuel technology." Renewable energy alone includes solar photovoltaics, solar thermal, wind, hydropower, geothermal, and biomass, which all can be implemented either through large centralized facilities or through distributed systems via large electrical energy distribution grids, microgrids, and offgrid applications. When considering the relationship of renewable energy to water and food, the effects become highly dependent on the type of energy, the location, and the method of deployment. Water will be conserved by the use of solar photovoltaics and wind energy which have few demands for water apart from construction and cleaning. For example, wind turbines use very little to no water, have a small footprint, and allow for growing crops in conjunction with the wind farms, often supporting farmers through small payments for land access (Fthenakis and Kim, 2009; Spang et al., 2014). Solar photovoltaics have very low water usage and distributed systems are often on tops of buildings with little to no land impact; centralized solar facilities do occupy land areas comparable to conventional energy. However, new research shows that crops can be grown in the shade under the solar panels depending on their installation (Fthenakis and Kim, 2009; Spang et al., 2014; Jossi, 2018).

Hydropower production involves withdrawing or restraining water, using it for a short period of time and returning it to the river water body without any significant reduction in quality or volume. Hydropower dams can also provide co-benefits to farmers in terms of more consistent access to water and control of flooding. However, large dams flood significant land areas and often displace many people, remove prime agricultural lands from production, and affect natural ecosystems and their services. Depending on their location, large reservoirs can also be inefficient due to large evaporative loses. On the other hand, small run-of-the-river or conduit-based hydropower systems may be an effective way to generate power and irrigate crops with little to no land conversion (Fthenakis and Kim, 2009).

In the evaluation of the technologies relevant to targets of SDG 7 with other targets, biofuels created the most uncertainty. Increased access to electricity produced by renewable energy can reduce dependence on wood and other biomass used for heating and cooking that causes deforestation-threatening regulating ecosystem services-and exposure to indoor air pollution (Pereira et al., 2011). However, biofuels generated from food crops or grown on land that could be used for food were seen to have the largest potential conflict with water and food with the largest land and water use per unit of energy generated (Spang et al., 2014; Trainor et al., 2016). It was recognized that the development of new cellulosic-based biofuels from agricultural wastes could provide an important secondary income stream for farmers.

Overall, our analysis indicates that renewable and other clean energy will result in a general net positive effect for the Energy SDG (SDG 7) and also for the water and food SDGs. However, as access to clean and affordable energy increases to meet this goal, careful attention to synergies with water, and food goals will need to be pursued to increase the potential for positive synergies and improvements over traditional energy sources. The exposed arguments mean also that depending on the mix of renewables used for achieving target 7.2, the consequences and trade-offs for and with other targets will strongly differ. Coupling our approach with models providing scenarios of the outputs of different possible energy mix may help to better evaluate the trade-offs between targets.

\section{LIMITATIONS OF THE APPROACH}

There are many considerations not analyzed in this methodology that can be further assessed. For example, mineral inputs are needed for achieving certain targets (e.g., for photovoltaic devises, agro-chemical production, water purification, etc.). However, the variety of minerals used in the different sectors as well as their heterogeneous availability would need a much more detailed analysis in order to integrate them in this approach. Similarly, infrastructure costs and labor that are needed have not been considered. There are many targets that require these investments and would ultimately share the investment. For example, targets 6.2 (sanitation) and 6.3 (water quality) would likely share water treatment infrastructure. Yet, some infrastructural developments may be too expensive for some developing countries. To reduce the complexity of these issues they are best considered with a more geographically focused area in mind.

Furthermore, the approach developed here does not account for cultural ecosystem services due to their complexity and difficulty to quantify and evaluate. However, for local applications 
where the cultural, management, and recreational contexts are well-known, it would be easy to expand the methodology in order to include the risks and benefits for such services.

We do not consider air, wind, temperature, solar radiation, or precipitation as inputs or the impacts that the WEF targets may have on climate targets. A further analysis of how SDG 13's (Take urgent action to combat climate change and its impacts) targets could impact the success of the WEF targets, and vice versa, would be beneficial. In the longer term, climate change and its extremes may have significant impacts on the interactions among the water, energy, and food sectors. The trend to replace carbon-based energy with renewables may, however, slow that trend and reduce these concerns. Also, in future studies, synergies and conflicts between the WEF targets and the targets of SDG 14 (life below water), 15 (life on land), and 11 (sustainable cities and communities) should be evaluated. This is especially important since the provision of ecosystem services will very much depend on the implementation of SDG 14 and 15. Moreover, the decoupling of food production and consumption areas due to urbanization may significantly change fuel and energy consumption through changes in (international) trade volumes and patterns.

Our analysis assumes that if two targets need a resource (e.g., water), they will compete for it. However, resource constraints may be partially addressed by developing their supply side. For example, water could be made available from desalinization plants or pumping (more) groundwater where these reserves exist. Groundwater that is heated underground can also play an important role in the energy supply for both power and heating (e.g., Lund and Boyd, 2015). The application of the approach developed in this study during periods of surface water scarcity in regions where groundwater use is intense (e.g., Mediterranean, Middle East, western North America) could elucidate important regional WEF Nexus issues that may affect the achievement of the SDGs at the national level.

The quantification approach developed in this study was made for a general case, based on expert knowledge and assuming mainly business as usual implementation and development plans (conventional agriculture, gray infrastructure, inequality, etc.) Accordingly, coarse assumptions on input and infrastructure needs as well as on the benefits and risks for ecosystem services were made for quantifying target interactions. The use of this approach requires defining the way a country or region aims at reaching the SDG targets, since SDGs establish what to achieve and when, but not how, so that countries and regions can develop different plans for doing so. This all means that the matrix can have very different results when the approach is used in a specific context or with a specific implementation pathway.

Although the interaction matrix evaluates only the interconnection between two sectors at a time, all three sectors, water, energy, and food, are intrinsically linked in many situations around the globe. With a specific area in mind, and concrete development pathways from policy making, this approach can be further developed to account for cascading effects, i.e., the consequences of a synergic or conflicting interaction between two targets on a third target.
Overall, the approach developed in this study offers a replicable, quantitative and criteria-oriented methodology for evaluating synergies and conflicts between SDG targets of the WEF domain.

\section{COMPARISON WITH SIMILAR STUDIES}

Fuso Nerini et al. (2018) and McCollum et al. (2018) analyzed based on literature review the interactions between the SDG 7 targets and the rest of the targets. Our results agree with the findings of both papers by indicating that the positive interactions between the SDGs substantially outweigh the negative ones. McCollum et al. (2018) also assessed the strength of interactions based on Nilsson et al. (2016) for SDG 7 as a whole and some group of targets from other SDGs. Unfortunately, they do not report the relationships for each target separately, so that a quantitative comparison is not possible, though both studies agree on various interactions and on the general positive magnitude of interactions.

Pradhan et al. (2017) analyzed synergies and trade-offs based on correlations of indicator values for all SDGs in 227 countries. They found that synergies outweigh trade-offs in general-in agreement with our results-and that there are more synergies than trade-offs within SDG 6 (100\% synergies in our study, $75 \%$ in their study). Some major differences can be observed, for example they found mostly synergies within SDG 2 (our study finds $40 \%$ of trade-offs), many nonclassified relationships within SDG 7 (our study finds only synergies), and trade-offs between access to energy services (target 7.1) and increase the share of renewables (target 7.2), while we assessed the both targets to be mutually reinforcing. Furthermore, they found high percentage $(\sim 50 \%)$ of trade-offs between SDG 7 and SDG 6, while we found only synergies. Since Pradhan et al. (2017) uses indicator data of the past, he accounts for resource competition and infrastructural needs, as we do. However, their pairwise correlations do not account for degradation of ecosystem services through the achievement of targets which indicators are not directly linked to those services. Also, and as opposed to our approach, their methodology is not able to capture alternative (future) pathways for which there would be a lack of indicator data. Thus, both studies and methodologies are complementary, with the one applied in Pradhan et al. (2017) more able to monitor progress, and the one developed here more able to project success or conflicts, and support decision makers in the design of implementation plans.

Mainali et al. (2018) qualitatively and quantitatively assessed target interactions of the SDGs 1, 2, 6, and 7 in the period of time 1990-2012 for some South-Eastern and Sub-Saharan African countries by means of network analysis techniques, correlation of indicators values, and advanced sustainability analysis. They found synergies between targets 2.1 and 7.1 and between 7.1 and 6.1, in agreement with our results. However, their results diverge regarding the interactions between the targets 2.3 and 6.4 (their Figure 9 indicates trade-offs but the text and the correlation of indicator values suggest synergies), while we 
found a reinforcing influence. Most importantly, Mainali et al. (2018) and Pradhan et al. (2017) show that the same approach when applied in different countries may yield very different results.

\section{CONCLUSIONS}

The SDGs provide us with an opportunity to improve each of the water, food, and energy sectors now to make them less vulnerable under future change and to optimize their relationships so the benefits in one sector are spread among the other two and in fact among all of the SDGs. Our analysis reveals that SDG 6 has the highest number of potential synergies, 124 positive interactions, and SDG 2 has the most negative interactions (26). The achievement of SDG 6, including sustainable management of water resources and improved quality and access of water will facilitate the achievement of SDG 2 and 7 targets. The negative interactions of SDG 2 targets are due to the high dependency of food production on water, energy, and land resources and to potential degradation of regulating ecosystems services through unsustainable farming practices. Thus, for food security to be achieved sustainably, careful and holistic policy implementation in the Water-Energy-Food Nexus framework is paramount.

Our results show that the targets receiving the most positive interaction scores are those that advocate cooperation and are policy focused. Target 6.5 , implement integrated water resource management, provides a framework for all levels of government in many aspects of planning and management processes. Target 7.a, enhance international cooperation to facilitate clean energy research and technology, if achieved, will increase and improve clean energy sources that will reduce the burden on water resources and the degradation of ecosystems caused by energy production based on fossil fuels. Thus, our findings indicate that cooperation across all levels of government and civil society may be a key tool for the success of the SDGs.

The approach used in this paper shows how each of the WEF targets are interconnected with one another and what opportunities exist for mutually beneficial solutions in terms of investments and programmes, as well as the possibilities of one target impairing another. The analysis of SDG targets interactions can also aid in policy development for target achievement by providing a broader scope of the connections between the SDGs. Policy makers can use this methodology to take into account a more holistic view of possible outcomes from certain action or inaction. This analysis has been done on a broad global scale, attempting to factor in considerations of time, space, economics and feasibility. However, by using a quantitative analysis the process can be reproduced within other contexts, being suitable to be scaled down to suit a specific a

\section{REFERENCES}

Adenle, A. A., and Ammann, K. (2015). Role of Modern Biotechnology in Sustainable Development; Addressing Social-Political Dispute of GMOs that Influences Decision-Making in Developing countries. Brief for GSDR. Available online at: https://sustainabledevelopment.un.org/content/ documents/6539117_Adenle_Addressing\%20Social_Political\%20Dispute country or an ecosystem, and even be applied for analyses of targets from other SDGs. The study also supports an assessment of the ways in which the WEF Nexus approach can contribute to the achievement of the SDGs and to identify co-benefits that could be developed between the SDGs and the WEF Nexus implementation.

In summary, it should be recognized that, apart from infrastructure investments, much of the economic rationale for achieving water SDGs will come from the choices we make in developing the resource sectors of water, energy, and food. While this discussion deals with the macroscale effects, the connections themselves occur over many different scales, and innovation and scale interactions can move from the local level to trigger changes and disruptions that can influence the entire global balance. Given the important insights this study has provided regarding the relationships among the targets for energy, water, and food, the SDG stakeholder and research communities for each of these sectors should reach out to the WEF Nexus community to see how they can benefit from collaboration.

\section{AUTHOR CONTRIBUTIONS}

RL and CC conceived the research idea. MF designed and developed the research methodology and programmed the equations. JE-C provided input to energy analysis, MF analyzed synergies and trade-offs in the food and water domain, CC and $\mathrm{RL}$ assessed the risks and benefits for ecosystem services. MF and CC performed the calculations. All authors provided critical feedback and helped shape the research and manuscript.

\section{ACKNOWLEDGMENTS}

This work was authored in part by the National Renewable Energy Laboratory, operated by Alliance for Sustainable Energy, LLC, for the U.S. Department of Energy (DOE) under Contract No. DE-AC36-08GO28308. The views expressed in the article do not necessarily represent the views of the DOE or the U.S. Government. The U.S. Government retains and the publisher, by accepting the article for publication, acknowledges that the U.S. Government retains a nonexclusive, paid-up, irrevocable, worldwide license to publish or reproduce the published form of this work, or allow others to do so, for U.S. Government purposes.

\section{SUPPLEMENTARY MATERIAL}

The Supplementary Material for this article can be found online at: https://www.frontiersin.org/articles/10.3389/fenvs. 2018.00112/full\#supplementary-material

\%20of\%20GMOs\%20that\%20Influences\%20Decision_Making\%20in \%20Developing\%20countries.pdf (Accessed June 22, 2018).

Azadi, H., Ghanian, M., Ghoochani, O. M., Rafiaani, P., Taning, C. N., Hajivand, R. Y., et al. (2015). Genetically modified crops: towards agricultural growth, agricultural development, or agricultural sustainability? Food Rev. Int. 31, 195-221. doi: 10.1080/87559129.2014. 994816 
Benson, D., Gain, A., and Rouillard, J. (2015). Water governance in a comparative perspective: from IWRM to a 'nexus' approach? Water Altern. 8, 756-773. Available online at: http://gfzpublic.gfz-potsdam.de/pubman/item/ escidoc:881911:3/component/escidoc:885890/881911.pdf

Bhaduri, A., Ringler, C., Dombrowski, I., Mohtar, R., and Scheumann, W. (2015). Sustainability in the water-energy-food nexus. Water Int. 40, 723-732. doi: 10.1080/02508060.2015.1096110

Biggs, E. M., Bruce, E., Boruff, B., Duncan, J. M., Horsley, J., Pauli, N., et al. (2015). Sustainable development and the water-energy-food nexus: a perspective on livelihoods. Environ. Sci. Policy, 54, 389-397. doi: 10.1016/j.envsci.2015. 08.002

Connor, R., Renata, A., Ortigara, C., Koncagül, E., Uhlenbrook, S., LamizanaDiallo, B. M., et al. (2017). The United Nations World Water Development Report 2017. Wastewater: The Untapped Resource. The United Nations World Water Development Report.

Cooley, H., and Donnelly, K. (2013). Water-Energy Synergies: Coordinating Efficiency Programs in California. Pacific Institute. Available online at: http:// pacinst.org/wp-content/uploads/2013/09/pacinst-water-energy-synergiesfull-report.pdf (Accessed June 22, 2018).

Coopman, A., Osborn, D., Ullah, F., Auckland, E., and Long, G. (2016). Seeing the Whole: Implementing the SDGs in an Integrated and Coherent Way. London: Stakeholder Forum. Available online at: https://www.stakeholderforum.org/ fileadmin/files/SeeingTheWhole.ResearchPilotReportOnSDGsImplementation. pdf (Accessed June 22, 2018).

Dean, J.M. (2002). Does trade liberalization harm the environment. A new test. Can. J. Econ. 35, 819-842. doi: 10.1111/0008-4085.00155

Endo, A., Tsurita, I., Burnett, K., and Orencio, P.M. (2017). A review of the current state of research on the water, energy, and food nexus. J. Hydrol. 11, 20-30. doi: 10.1016/j.ejrh.2015.11.010

Fader, M., Gerten, D., Thammer, M., Heinke, J., Lotze-Campen, H., Lucht, W., et al. (2011). Internal and external green-blue agricultural water footprints of nations, and related water and land savings through trade. Hydrol. Earth Syst. Sci. 15, 1641-1660 doi: 10.5194/hess-15-1641-2011

Fthenakis, V., and Kim, H. (2009). Land use and electricity generation: a life-cycle analysis. Renew. Sustain. Energy Rev. 13, 1465-1474. doi: 10.1016/j.rser.2008.09.017

Fuso Nerini, F., Tomei, J., To, L.S., Bisaga, I., Parikh, P., Black, M., et al. (2018). Mapping synergies and trade-offs between energy and the sustainable development goals. Nat. Energy 3, 10-15. doi: 10.1038/s41560-0170036-5

Gupta, J., Baud, I., Bekkers, R., Bernstein, S., Boas, I., Cornelissen, V., et al. (2014). Sustainable Development Goals and Inclusive Development. POST2015/UNUIAS Policy Brief(5). Available online at: http://collections.unu.edu/eserv/UNU: 2567/Post2015_UNUIAS_PolicyBrief5.pdf (Accessed June 22, 2018).

ICSU/ISSC (2015). Review of the Sustainable Development Goals: The Science Perspective. Paris: International Council for Science (ICSU). Available online at: https://www.icsu.org/cms/2017/05/SDG-Report.pdf (Accessed June 22, 2018).

Jossi, F. (2018). Putting the 'farm' back in solar farms: study to test ag potential at $P V$ sites, Midwest Energy News, January 22, 2018. Available online at: http://midwestenergynews.com/2018/01/22/putting-the-farm-backin-solar-farms-study-to-test-crop-potential-at-pv-sites/ (Accessed June 22, 2018).

Lele, U. (2013). Good governance for food water and energy security. Aquat. Proc. 1, 44-63. doi: 10.1016/j.aqpro.2013.07.005

Lund, J.A., and Boyd, T. (2015). Direct utilization of geothermal energy 2015 worldwide review. Geothermics 60, 66-93. doi: 10.1016/j.geothermics.2015.11.004

Mainali, B., Luukkanen, J., Silveira, S., and Kaivo-oja, J. (2018). Evaluating synergies and trade-offs among Sustainable Development Goals (SDGs): explorative analyses of development paths in South Asia and Sub-Saharan Africa. Sustainability 10:815. doi: 10.3390/su10030815

McCollum, D.L., Gomez Echeverri, L., Busch, S., Pachauri, S., Parkinson, S., Rogelj, J., et al. (2018). Connecting the sustainable development goals by their energy inter-linkages. Environ. Res. Lett. 13:033006. doi: 10.1088/1748-9326/aaafe3/meta

Nilsson, M., Griggs, D., and Visbeck, M. (2016). Map the interactions between Sustainable Development Goals. Nature 534, 320-322. doi: 10.1038/534320a

Pardoe, J., Conway, D., Namaganda, E., Vincent, K., Dougill, A. J., and Kashaigili, J. J. (2017). Climate change and the water-energy-food nexus: insights from policy and practice in Tanzania. Clim. Policy 18, 863-877. doi: 10.1080/14693062.2017.1386082

Pereira, M., Sena, J., Freitas, M., and da Silva, N. (2011). Evaluation of the impact of access to electricity: a comparative analysis of South Africa, China, India and Brazil. Renew. Sustain. Energy Rev. 15, 1427-1441. doi: 10.1016/j.rser.2010.11.005

Pittock, J., Orr, S., Stevens, L., Aheeyar, M., and Smith, M. (2015). Tackling trade-offs in the nexus of water, energy and food. Aquat. Proc. 5, 58-68. doi: 10.1016/j.aqpro.2015.10.008

Pradhan, P., Costa, L., Rybski, D., Lucht, W., and Kropp, J. P. (2017). A Systematic Study of Sustainable Development Goal (SDG) Interactions. Earth's Future 5, 1169-1179. doi: 10.1002/2017EF000632

Ringler, C., Bhaduri, A., and Lawford, R. (2013). The nexus across water, energy, land and food (WELF): potential for improved resource use efficiency? Curr. Opin. Environ. Sustain. 5, 617-624. doi: 10.1016/j.cosust.2013.11.002

Rockström, J., Williams, J., Daily, G., Noble, A., Matthews, N., Gordon, L., Wetterstrand, H., et al. (2017). Sustainable intensification of agriculture for human prosperity and global sustainability. Ambio 46:4. doi: 10.1007/s13280-016-0793-6

Scott, A. (2017). Making Governance Work for Water-Energy-Food Nexus Approaches. Working Paper. London: Climate and Development Knowledge Network (CDKN). Available online at: https://cdkn.org/wp-content/uploads/ 2017/06/Working-paper_CDKN_Making-governance-work-for-waterenergy-food-nexus-approaches.pdf (Accessed June 22, 2018).

Sheahan, M., Barrett, C., and Goldvale, C. (2016). The Unintended Consequences of Agricultural Input Intensification: Human Health Implications of Agro-chemical Use in Sub-Saharan Africa. Working Paper Series $N^{\circ} 234$ African Development Bank. Abidjan.

Spang, E., Moomaw, W., Gallagher, K., Kirshen, P., and Marks, D. (2014). The water consumption of energy production: an international comparison. Environ. Res. Lett. 9:105002. doi: 10.1088/1748-9326/9/10/105002

Trainor, A., McDonald, R. I., and Fargione, J. (2016). Energy sprawl is the largest driver of land use change in United States. PLoS ONE 11:e0162269. doi: 10.1371/journal.pone.0162269

Tscharntke, T., Clough, Y., Wanger, T.C., Jackson, L., Motzke, I., Perfecto, I., et al. (2012). Global food security, biodiversity conservation and the future of agricultural intensification. Biol. Conserv. 151, 53-59. doi: 10.1016/j.biocon.2012.01.068

UN-Water (2016) Water and Sanitation Interlinkages across the 2030 Agenda for Sustainable Development. Geneva. Available online at: http://www.unwater.org/ app/uploads/2016/08/Water-and-Sanitation-Interlinkages.pdf (Accessed June 22, 2018).

Yillia, P. T. (2016). Water-Energy-Food nexus: framing the opportunities, challenges and synergies for implementing the SDGs. Österr. Wasser Abfallwirtsch. 68, 86-98. doi: 10.1007/s00506-016-0297-4

Conflict of Interest Statement: The authors declare that the research was conducted in the absence of any commercial or financial relationships that could be construed as a potential conflict of interest.

Copyright (c) 2018 Fader, Cranmer, Lawford and Engel-Cox. This is an open-access article distributed under the terms of the Creative Commons Attribution License (CC $B Y)$. The use, distribution or reproduction in other forums is permitted, provided the original author(s) and the copyright owner(s) are credited and that the original publication in this journal is cited, in accordance with accepted academic practice. No use, distribution or reproduction is permitted which does not comply with these terms. 